Homonormativity or Queer Disidentification?: Rural Australian Bisexual Women's Identity Politics

Ruby Grant

(School of Social Sciences) University of Tasmania, Australia

Meredith Nash

(School of Social Sciences) University of Tasmania, Australia

Corresponding author:

Ruby Grant, School of Social Sciences, University of Tasmania, Private Bag 22,

Hobart, Tasmania 7001, Australia. Telephone: +61 36226 1556. Email:

rfgrant@utas.edu.au 


\title{
Homonormativity or Disidentification?: Rural Australian Bisexual Women's Identity Politics
}

\begin{abstract}
Recent research shows that queer youth increasingly reject traditional sexual labels in favour of more fluid identifications. Despite well-rehearsed debates around queer identity politics under neoliberalism, there is a dearth of research examining how queerness is understood and expressed in rural Australia. To address this knowledge gap, this article examines bisexual and queer young women's understandings of sexual labels in Tasmania, Australia. Drawing on Jose Esteban Muñoz's disidentifications, we argue that while neoliberalism and homonormativity do influence rural queer women's identity politics, their lived experiences present specific challenges that draw attention to the urban-centricity of homonormativity.
\end{abstract}

Keywords: identity labels, neoliberalism, queer, rural, sexuality

\section{Introduction}

Recent research in the United States and the United Kingdom reveals that young women are placing less importance on traditional sexual identity labels (e.g. "gay," “lesbian) (see Callis, 2014). Similar trends are also observed in Australia (see Albury, 2015). Some scholars argue that growing acceptance of same-sex attraction in the West is influencing the ways in which young people understand and articulate sexual 
identities (Ghaziani, 2011; Richardson, 2005). In particular, Adams et al. (2014: 459) argue that the increasing normalisation of diverse sexualities is reducing the "strategic importance of identity categories" for young people, causing them to abandon common identity labels. In contrast, some argue that young people, particularly women, are expanding their understandings of gender and sexuality, subsequently broadening their use of increasingly specific and alternative sexual categories (Robards et al., 2018). While there is a growing body of interdisciplinary work examining these nuances of contemporary queer identity politics, few studies focus specifically on young women's experiences. In particular, there is a dearth of Australian qualitative research that provides in-depth data on how bisexual and queer young women's identities are understood and expressed in rural spaces. These knowledge gaps suggest a compelling need to explore bisexual and queer women's lived experiences of identity in rural Australia.

Using Jose Esteban Muñoz’s (1999) “disidentifications” as a theoretical framework, in this paper we draw on qualitative interviews to examine the different ways rural Australian young women understand, claim, and, in some cases, reject sexual identity labels. In so doing, we argue that neoliberalism shapes how Australian bisexual and queer women negotiate sexual self-labelling by shifting sexuality from the political into the personal. Although neoliberalism inflects the lives of urban and rural queer young women in similar ways (Richardson, 2005), findings reveal rural women's lived experiences of biphobia suggest a failure of "homonormativity" (see Duggan, 2002) to extend into these spaces. By deploying Muñoz's (1999) “disidentifications," we shall show how "dis-identifying" is a survival mechanism for rural bisexual and queer women. Applying Muñoz's (1999) perspectives here necessarily complicates 
the dichotomous discourse around accepting or rejecting sexual identity labels and affords marginalised subjects new agency in neoliberal rural contexts.

\section{Theoretical Framework: Neoliberalism, Homonormativity, and Disidentification}

Scholars from a range of disciplines observe that lesbian, gay, bisexual, transgender, and queer (LGBTQ) youth in the West are defining themselves less in terms of their sexuality or are rejecting traditional sexual identity labels (see Adams et al., 2014; Coleman-Fountain, 2014; Hegna. 2007). Several explanations for this shift are offered. Some argue that increasing normalisation of homosexuality has resulted in greater freedom and choice in contemporary narratives of sexual identity whereby young people no longer experience same-sex attraction as unusual and therefore do not feel the need to invoke politicised collective identity categories (Savin-Williams, 2005). Some theorists suggest that neoliberalism is a key factor influencing these shifts from collective, politicised sexual identities towards these more specific, individualised identifications (see Duggan, 2012; Ghaziani, 2011; Richardson, 2005). In this article, we explore how these neoliberal approaches to identity are influencing bisexual and queer young women's sexual self-labelling in rural Australia.

Whilst an expansive discussion of neoliberalism is beyond the scope of this paper, we shall briefly explain our use of the concept given the well-rehearsed critiques of its routinisation in social theory (see Bell and Green, 2016). Neoliberalism has been referred to as "shorthand for an array of complex economic, political, and cultural dynamics" (Grzanka et al., 2016: 300). While much of the theorising situates neoliberalism as a political theory based on free market economics (e.g. Harvey, 
2005), other scholars argue that neoliberalism has much broader social implications (e.g. Chen, 2013). Drawing on Foucault's concepts of governmentality and biopolitics, Rose (1999) demonstrates how, under neoliberalism, citizen-subjects are positioned as self-governing individuals who are responsible for their own individual choices, while state responsibility for social provision is withdrawn and privatised. In light of debates that call for a more nuanced deployment of neoliberalism, in this article, we define neoliberalism as the constellation of practices by which the state influences and evaluates individuals' behaviours through self-discipline and surveillance (Grzanka et al. 2016: 298). We also draw influence from Puri's (2016: 308) definition of neoliberalism as a hegemonic ideology. However, as Puri (2016: 309) importantly elaborates, the relationship between neoliberalism and sexuality is not necessarily linear, but "co-constitutive" - meaning that just as neoliberal policies produce certain sexualities, sexual cultures can also intervene in neoliberalism.

Feminist and queer scholarship illuminates how neoliberal ideologies transform gender and sexuality politics. Lisa Duggan (2002) argues that neoliberalism inflects contemporary LGBTQ rights agendas by shifting the focus from politicised collective identity-based action to calls for assimilation and individualised rights and freedoms (see also Ghaziani, 2011; Richardson, 2005). Scholars argue that neoliberal ideologies implore people to move away from embracing traditional collective identity categories and to instead construct their own individualised, but apolitical and private, sexual identities (see Adams et al., 2014; Coleman-Fountain, 2014; Hegna, 2007; Stein, 2010). Duggan (2002: 179) describes this shift as the "new homonormativity," a paradigm where privileged "mainstream" (white, urban, middle-class, cisgender, monogamous) gay men and lesbians are positioned as "ordinary, normal citizens" 
who "do not contest dominant heteronormative assumptions and institutions, but uphold them while promising the possibility of a demobilised gay constituency and a privatised, depoliticised gay culture anchored in domesticity and consumption.” Here, the neoliberal identity politics of homonormativity position LGB communities in terms of their "sameness" to heterosexuals on the grounds of personal "lifestyle and values"(Duggan, 2002: 179-180), while also locating sexuality as a private, individualised experience that is merely one internal "thread" of our identities, rather than a public, "core identity" (Seidman, 2013: 9-10). In this respect, we argue that homonormativity encourages the de-emphasising of sexuality as a core identity, which is reflected in youth rejections of traditional collective-identity labels (see Albury, 2015; Coleman-Fountain, 2014; Hegna, 2007; Robinson, 2013).

To examine how rural bisexual and queer women navigate the complex politics of identity under neoliberalism, our approach is informed by a queer theoretical framework drawing on the work of cultural theorist, Jose Esteban Muñoz. In his 1999 book, Disidentifications: Queers of Colour and the Performance of Politics, Muñoz examines the ways queer people of colour in the US are excluded from the white homonormativity of LGBTQ politics. Muñoz challenges the totalising explanations of identities as either essentialist or socially constructed, instead theorising that the realities of identity formation vary among individuals and socio-historical contexts (1999: 5-6). Medina (2003: 663-664) argues that Muñoz's concept of disidentification is useful in unpacking complex identity politics because it captures the "structural messiness" of the "interlocking networks of similarities and differences that sustain identity." 
Considering the "identities-in-difference" of queer people of colour in the US, Muñoz (1999: 7) demonstrates how new subject positions are formed out of “disidentification” with dominant structures of identity. Muñoz theorises disidentification as a third mode of dealing with dominant ideologies, a middle ground between assimilation ("identification") and total opposition to hegemonic identity structures (“counter-identification”) (1999: 11). Butler (1993: 219) similarly suggests that disidentification is an "experience of misrecognition, this uneasy sense of standing under a sign to which one does and does not belong." Muñoz argues that disidentification can be a "survival strategy," a reflexive way of navigating oppressive public sphere for individuals inhabiting the borders of intersecting experiences (1999: 4). However, Muñoz (1999: 13) emphasises that disidentification is not merely a process of "picking and choosing what one takes out of an identification." Rather, it involves a deeper transformation of one's identity and relations with others (Medina, 2003: 664). For Muñoz (1999: 12), new subject positions arise as individuals disidentify with established identities and tactically "work on, within, and against" dominant cultural forms, such as normative sexual and gender roles, behavioural standards for sexual identity, and identity boundary maintenance. Thus, Muñoz's (1999) concept illuminates the reflexive identity work involved in (re)claiming sexual identity labels. In this article, we use Muñoz's framing of this complex identity work to explain how homonormativity inflects rural Australian bisexual and queer women's sexual self-labelling in different ways.

\section{Identity Politics in the Bush? Theorising Rural Queerness}

Most of what is known about neoliberalism and queer sexuality is derived from 
geographical studies of urban settings in the Global North. There is a dearth of sociological scholarship focusing on the experiences of LGBTQ people in rural Australia or elsewhere. Bell and Valentine (1995) were among the first to call for a richer understanding of rural queer experience in their germinal paper, 'Queer Country: Rural Lesbian and Gay Lives.' Here, they introduce UK gay and lesbian identity, relations and situatedness in rural spaces. Despite Bell and Valentine's (1995) invitation to "queer the countryside", most empirical studies continue to focus on the importance of urban space for LGBTQ communities and identity. This "metrocentrism" in queer research and theory can be explained by the popular "metanarrative" or "formula story" of the "oppressed rural gay," who escapes the ignorance and homophobia of the rural small town by moving to the city - a place of freedom and possibility from which to come out and live as LGBTQ (see Crawford, 2017; Halberstam, 2005). However, these geographies of "gay urban space" focus predominantly on gay men. With a few exceptions (e.g. Brown-Saracino, 2015; Kazyak, 2012), lesbian, bisexual, and queer women's identities are invisible in dominant queer narratives of identity and space.

There is very little research examining LGBTQ experiences in rural Australia (e.g. Gorman-Murray et al., 2008). Although there is a large body of scholarship on rural Australian youth, most studies continue to focus on heterosexual experiences and sexual cultures (Bishop, 2013; Hillier et al., 1999; Senior et al., 2014). National surveys and reports provide a snapshot of the critical sexual health and safety issues facing rural LGBTQ Australians. For example, Growing Up Queer, a national report on Australian LGBTQ young people shows that geographical location impacts queer young people's choices to come out and their perceptions of acceptance and safety 
(Robinson et al., 2014). Specifically, rural youth are less likely to report positive coming out experiences and have poorer mental health compared to their heterosexual peers (see Robinson et al., 2014). Given these disparities, the present study seeks to trouble the metrocentrism of queer research by examining whether and how homonormativity influences queer young women's sexual self-labelling in rural Australia.

\section{Method}

This article draws on data from a qualitative study investigating the experiences of gender, sexuality and sexual health in a sample of 15 women in Tasmania, Australia from 2015-2016. Located off the southeast coast of the Australian mainland, Tasmania is an isolated, largely rural island state with a population of approximately 500,000 people. Like other rural Australian communities, Tasmania has a higher unemployment rate, lower levels of post-school qualifications, and lower weekly earnings than the Australian average (BS 2012). Additionally, Tasmania has a unique health profile, with some of the highest rates of obesity, smoking, disability, and chronic illness in the country (ABS, 2014). Tasmania was the last Australian state to decriminalise homosexuality in 1997, the effects of which are still felt in the community today (Baird, 2006). Tasmania's geographical isolation, its unique health profile, and significant LGBTQ social history make it a compelling site to study contemporary queer identity politics.

Participants were recruited using purposive and snowball sampling methods.

Snowballing is a technique often used when researching groups that may be hidden or 
hard to access, but is also fruitful in making use of participants' shared identity and group membership (Babbie, 2014: 200-201; for examples, see Brown-Saracino, 2014). Through her involvement in the local LGBTQ community, Author 1 made use of her personal and professional networks and the often "close-knit" nature of rural LGBTQ communities (see Kazyak, 2012). This process involved placing advertisements inviting potential participants to contact the researchers in public places (university campus, health clinics, local organisations), targeted social media advertising in LGBTQ social groups, and in-person recruitment at social events hosted by a local LGBTQ advocacy organisation. All contact with participants was conducted via email or direct messaging through a Facebook page that established to promote the research. Given the focus of the broader study on rural young women's sexuality and sexual health, inclusion criteria were self-identified women aged between 18-30 years, same-gender attracted or LGBTQ, with experience accessing sexual healthcare in Tasmania. Sample size was based on consideration of the study design, nature of the topic, and quality of the data.

Prior to interviews participants were provided with an information sheet explaining the aims of the research, as well as consent forms to consider. Upon obtaining participants' informed consent, semi-structured interviews were conducted by Author 1, a female doctoral candidate in her mid-twenties who identifies as bisexual. Interviews lasted up to two hours and were held in mutually convenient public locations (university campuses, cafes, libraries). All interviews were conducted using an interview guide based on relevant literature and the key research objectives. Interviews focused on a range of open-ended questions about gender, sexuality, sexual health, and healthcare experiences. Demographic information was collected in 
a questionnaire. Interviews were audio-recorded and transcribed verbatim with consent. This project was approved by the University of X Human Research Ethics Committee as complying with the National Health and Medical Research Council's (NHMRC) National Statement on Ethical Conduct in Human Research (2007). In line with the committee's recommendations, participant protection strategies were prioritised at all stages of the design, conduct, and reporting of the project. Data has been de-identified and pseudonyms chosen by the participants are used in all reporting of the data.

The interviews were coded and analysed thematically with QSR NVivo (v.11.2.2 Mac) Loosely informed by a Grounded Theory approach (see Corbin and Strauss, 2015) data was analysed first by "open coding”, taking note of any striking words, phrases, and themes emerging from the data. Once common themes were identified, thematic categories, or, nodes were created in NVivo and relevant data was coded to those nodes. To ensure the validity of this thematic analysis and inter-coder reliability of the coding system, Author 2 provided critical feedback on the initial interpretation of the data. During this initial phase of analysis we coded participants' discussions of sexual identity labels into two inductive themes: "Importance of Labels" and “Ambivalence to Labels.” When exploring ways to interpret this data, Muñoz's (1999) work was identified as a potentially useful framework because of the similarities between our inductive codes and Muñoz's (1999) concepts of "identification" and "counter-identification". With this framework in mind, we revisited the initial analysis and identified new ways to re-structure the nodes and build meaning from the findings. Here, we looked for complexities within/between the nodes and explored how Muñoz's (1999) concept of disidentification applied to 
these.

Participants were between the ages of 19 and 26, with a mean age of 20 years. Most participants described themselves as white, middle-class, and tertiary educated.

Eleven women identified as bisexual or pansexual, and four identified as queer or "other" (e.g. panromantic-asexual, fluid). We believe it is necessary to acknowledge that the voices of transgender women and queer women of colour are regrettably absent from this study. A common criticism of self-selection and snowballing recruitment techniques in social research is that they draw non-representative, often homogenous samples (Babbie, 2014: 200-201). In particular, in sexualities research, such recruitment techniques result in an overrepresentation of white, middle-class, and tertiary-educated participants (Kitzinger, 1987: 88). The placement of recruitment materials is a critical factor here, as posting research advertisements in (physical and virtual) LGBTQ spaces is more likely to reach an audience of potential participants who are "out" and active in queer "scenes" that are often characterized by whiteness (Cohen, 1997; Sanchez, 2017).

Furthermore, researcher identity can shape who participates in social research. For example, Kitzinger (1987: 88) observes that her "obvious whiteness and middle-classness severely limited the extent to which [she] could be perceived as an 'insider' by some women." Similarly, in our study, while Author 1's identity aligned with the participants' as a young queer woman, her whiteness and status as a middle-class academic from an urban area likely influenced who self-selected into the study. Therefore, it is important to recognise these limitations and be aware of how intersecting privileges of whiteness and class shape the findings of this study. We 
acknowledge that the stories shared in this article are specific to our participants' experiences and not the LGBTQ community as a whole.

\section{Findings}

Following thematic analysis this section is structured in three parts: 1) Rejecting Labels, 2) Embracing Labels, 3) Disidentification. In the first part of the analysis, participants' accounts align with the homonormative emphasis on individuality, which encourages them to reject collective identity politics and labels. In contrast, some participants still emphasise the importance of claiming public sexual identities in order to find community and belonging in isolating rural contexts. Other participants offer nuanced accounts of strategic forms of disidentification, or, reflexive identity work as a survival strategy to navigate homonormative discourses from both within and beyond LGBTQ spaces. These findings reveal the complex ways in which neoliberalism shapes rural bisexual and queer young women's understandings of sexual identities.

Homonormativity and Rejecting Labels: "I Just Live My Life"

In line with recent studies of LGBTQ youth (e.g. Albury, 2015; Callis, 2014), no participants in our study identified as "lesbian." Growing up during a time of increasing LGBTQ equality in the West, for the majority of the participants, their frustration with labels largely stems from a neoliberal perception of ordinariness and a desire to be seen as individuals rather than political or minority stereotypes (see also Adams et al., 2014). For example, Isabelle (21, queer) describes her upbringing as 
"very progressive," adding that she never had to "come out" to her family, "because it's just not a big deal." When asked about her understanding of her sexuality, Isabelle explains:

I'm mostly attracted to guys... but I'm also attracted to girls and other genders, so I can't really... I don't know what the specific label is and I kind of can't be bothered finding the specific label. I'm just me. I know I'm not straight. And I guess that's just been... Enough.

Carrie (23, bisexual) expresses a similar ambivalence when asked about her sexuality, explaining:

I'm a private person. I'm really not into identity politics, or anything like that. It's just not something that really bothers me. Like, I don't think about it at all. (laughs) I just live my life.

Like Isabelle, Carrie did not have an "official coming out event" and did not remember when or how she first defined her sexuality, preferring to reject "identity politics" with an appeal to the ordinary: "I just live my life." Extracts from Carrie and Isabelle reflect the neoliberal politics of normalisation in their (re)location of their sexualities as personal or "private", "not a big deal," not a larger part of their public identities. Cohler and Hammack (2007) refer to this as the "narrative of emancipation," a freeing of oneself from the pressures and restrictions of labels, in favour of individuality. This phenomenon aligns with homonormativity (Duggan, 2002). Here, the neoliberal refrain of being an individual who "just lives their life" 
not "bothered" or restricted by "identity politics" also intersects with Savin-Williams" (2005) notion of the "unremarkable gay," as these participants want to be seen as "ordinary" individuals rather than members of a politicised minority group identity (see also Coleman-Fountain, 2014). In line with Kazyak (2012), participants' rejection of collective sexual identity labels could be interpreted as a homonormative response to their rural context. Similarly, for our rural Tasmanian participants, positioning sexuality as a private, unremarkable aspect of their identities allows them to "just live [their] life" in a context that has been historically unsafe for queer people. This reading of homonormativity in queer rural space importantly demonstrates how neoliberal and homonormative discourse can be expressed differently in rural contexts compared to urban, and the implications this can have for young women's identity practices and narratives.

Countering Homonormativity and Embracing Labels: "To Give it a Name, To Give it a Voice”

In contrast to participants who reject sexual identity labels in a homonormative rural context, others discuss the continuing importance of identity categories. Muñoz (1999: 7) defines identification as "a psychological process whereby the subject assimilates an aspect, property or attribute of the other and is transformed, wholly or partially, after the model the other provides.” In line with this definition, claiming identity labels and having these recognised and understood was important for some participants' self-acceptance, sense of belonging, and broader recognition in isolating rural and regional spaces: 
For me, the labels that I've given myself, they're to find other people like me and to explain... in as little words as possible... who I am. Rather than... um... spend time going 'well, is this it? Is this it? I don't know!' Um. Whereas, if I can just go, 'oh, well, I'm This' that's fine. That's a lot simpler. (Harley, 19, panromantic-asexual)

[Labeling] can be a way of finding some security in yourself.. yeah.. to sort of to be able to... find a label for yourself.. can be as comforting as to deny the labels that other people give you. I think. (Evie, 26, pansexual)

I think everyone likes to have a name, or a label for it, so they feel, like, normal and things. Otherwise it's a bit hard, you know? (Middy, 19, fluid)

Compared to participants who rejected static labels, these women's experiences of sexual self-labelling reflect Muñoz's paradigm of the "good subject" (1999: 11). For Muñoz (1999: 11), the "good subject" is one who "chooses the path of identification with discursive and ideological forms," which, in this case, can be understood as the unambiguous claiming of a static identity label. Similarly, for Hekman (2004: 7) "our personal identity makes us different from everyone else. Our public identity identifies us as the same as particular others." The most important function of identity labels for these participants is to make sense of and articulate identity to themselves and to others - a bridging of their personal and public identities. For example, as Middy's account demonstrates, claiming a clear identity label to explain otherwise complex lived experiences is positioned as legitimising or normalising their identities. Similarly, as Robinson (2013: 23) outlines, "identities bond people together, identify 
insiders and outsiders, enable political action on behalf of the group, and frame concepts such as disclosure, outing or community belonging." From these perspectives, the labels participants chose are their "public identities" that communicate selfhood and connect them to others, while their internal understandings and negotiations of these labels comprise their "personal identities" (Hekman, 2004: 7; see also Seidman, 2013: 10). Here, claiming a label is an "empowered" choice, allowing rural young women to be reflexive and to articulate their identity and experiences "in as little words as possible," rather than being unintelligible and silent.

Claiming a sexual identity label is important to these women who previously had difficulty articulating their experiences in rural Tasmania. For example, several bisexual women reported a perception that while gay and lesbian identities were generally understood and accepted, there is limited awareness and visibility for bisexual and queer identities in their rural hometowns. Here, the women's use of terms like "pansexual" and "fluid" arguably troubles homonormativity as these labels reflect a politics of identity based on shared group membership ("the labels that I've given myself, they're to find other people like me"), while also troubling those queer identities that have become 'acceptable' or normalised under neoliberalism. In this context, explicit labeling is a way of "categorising to produce identity" in participants' rural contexts (Coleman-Fountain, 2014: 807; see also Hegna, 2007). Therefore, identity labels can provide ontological security, and also serve as an important means of articulating non-normative and potentially unintelligible experiences to others 
While homonormative discourse increasingly positions same-sex attraction as "ordinary," this seldom extends to bisexuality (Grant and Nash, 2018a). There is increasing evidence to suggest that bisexual and other plurisexual people (e.g. pansexual, queer) continue to experience stigma as a result of biphobia, or monosexism ("the belief that people can or should only be attracted to and engage in relationships with one sex and/or gender") (Flanders et al., 2016: 153). Monosexist discourses position bisexual women as claiming a bisexual identity for attention (Alarie and Gaudet, 2013), going through a "phase" (Diamond, 2003), or performing to attract the heterosexual male gaze (Boyer and Galupo, 2015). Incidentally, bisexual women report significantly poorer mental health and lower likelihood of selfdisclosure and community connection compared to lesbians (Balsam and Mohr, 2007). These stressors are further exacerbated for rural bisexual women, who often report feeling invisible in rural LGBTQ communities (see Grant and Nash, 2018b). Barefoot et al. (2015: 22) argue that "rural culture is often associated with traditional gender roles, conservatism, patriarchy, fundamental religiosity, heteronormative family structures, and conformity." Homonormative discourse can be deployed by (white, cisgender) gay men and lesbians in rural contexts to gain acceptance (Kazyak, 2012) in a way that is seldom available to bisexual and queer women, other than through erasure. Furthermore, as the concept of homonormativity is predominantly framed around urban, gay and lesbian subjects, to our knowledge no previous studies have examined how rural bisexual women understand and articulate sexuality labels in this context. In this section, we demonstrate how participants use disidentification as a survival strategy in a homonormative rural context, and as an act of resistance 
within exclusionary, monosexist identity politics.

Sedgwick (1990) observes that it is widely assumed that self-identification should align with one's public performance of sexual identity, and that this identity is assumed to be fixed over a lifetime (Albury, 2015: 652). These dominant models of sexual self-labelling and the subsequent analyses of these are seldom inclusive of bisexuality. Subsequently, many participants' understandings of bisexuality complicated these "normativising protocols," or dominant constructions of identity (see Muñoz, 1999: 11):

I think... Like, I've actually mostly had cis[gender] male partners I think... Or or more than women... But then it's like... ridiculous that I have quantified that in my head, oh I've had... I've slept with four women and six men, so I guess like... you know... It's not a numbers game. (Jayden, 20, pansexual).

I feel like bisexual does have that binary thing, like half of my sexual encounters have to be with girls and half of them have to be with guys... And that's really not how my sexual history reads... it suggests like an even 50:50 split, which is why I think people have such a huge issue with it... Like... As a bisexual person, it's like you have to recount your entire sexual history so people can divide it up and see if you are properly bisexual... (Sloane, 26, queer).

Here, participants reflect the commonly held perception of the "behavioural standard" for sexuality - the notion that someone is only "authentically" bisexual or queer if 
they have had equal amounts of sexual experience with both men and women, or a “50:50 split” (see Boyer and Galupo 2015; Rupp and Taylor 2010). Participants draw on mathematical imagery to demonstrate what can be interpreted as a sterile and disembodied notion of "quantifying" identity, desire, and sexuality. These behavioural standards prompt some participants to disidentify with bisexuality given the scrutiny they might face in using the term, for example:

I definitely feel like... (sighs) like I'm not properly.. gay.. like not a real lesbian.. I've got this gay friend who once referred to me as being "part time gay." Which is really dumb because... (laughs) I mean... I'm pan[sexual]... I identify as pan now... because I feel I have to.. Cause.. yeah.. because if I say I'm bi[sexual] people just go, “oh but you date guys so...?” There's just a lot of slut-shaming. It's ridiculous! (Francesca, 20, pansexual)

Like, what makes you queer? It's ridiculous! The idea that ... Oh you just have to like sleep with this many women, and like, have this kind of hair cut and (laughing) It's like yeah just get a septum piercing... and then we'll accept you as one of ours. It's not like a coffee card that you get stamped and then they're like "And here is your Queer Card!" like "you are real now!” Yeah it really delegitimises people when we have set expectations for what actually makes someone bi or queer... So yeah, I try to push back against that... I'd say I didn't use any labels at all just to avoid all that... (Frankie, 25, bisexual)

For Muñoz (1999: 8), the absence of intersectional approaches to difference within minority groups prevents some individuals from accessing collective identities. In line 
with Muñoz, Frankie's comments demonstrate the futility of policing queerness as an identity that intends to transcend definition and categorisation (see Ahmed, 2014). Frankie's use of the coffee card analogy - sexual identity membership as a process of quantifiably proving ones' loyalty - powerfully illustrates participant experiences of the reductive and dehumanising nature of explaining and authenticating bisexuality and queerness for others. This boundary policing similarly led Francesca to disidentify with bisexuality, rejecting the label in favour of "pansexuality." In contrast, Frankie continues to identify as "bisexual" in the hope of "transforming a cultural logic from within" (Muñoz 1999: 11). For Muñoz, it is these reflexive engagements with identity that differentiate disidentification from counteridentification - rather than rejecting labels entirely in favour of neoliberal individualism, disidentifying subjects respond to biphobia and monosexism by critiquing labels and reframing their identities in alternative ways.

These findings indicate that disidentification may be an important survival strategy for rural bisexual and queer young women. Disidentification is often strategic for participants because avoiding labels in favour of ordinariness or ambiguity allows them to redraw the lines of normality to avoid discrimination and stigma in a rural Tasmania where queer visibility is limited. This corresponds with Kazyak's (2012) US study finding that rural gay men and lesbians employ homonormative rhetoric to differentiate themselves from urban queers and emphasise their status as "good," “ordinary” rural people. Similarly, Coleman-Fountain (2014: 809) argues that “stereotypes are read into lesbian and gay labels, and deny a person's potential for an authentic identity beyond the caricatures of others.” By strategically using some labels rather than others, participants in this study engage in reflexive identity work to 
reduce stigma around those identities that are excluded from neoliberal "normativising protocols" of homonormativity.

\section{Discussion}

In this article, participants' narratives illustrate the fluidity and provisionality of contemporary young women's understandings of sexuality. As we argue, Muñoz's (1999) disidentification theory is especially useful to analyse the complex and often contradictory ways bisexual and queer young women navigate neoliberal identity politics in rural Australia. We found that while homonormative discourse can be strategically deployed to gain acceptance and belonging in rural contexts, it gains less traction for those whose identities are yet to be normalised. We suggest that through their disidentificatory work, bisexual and queer young women are opening up a politics of identity to potentially produce new ways of thinking about the contemporary sexual self-labelling beyond homonormativity.

While the women in this study recognise the importance of sexuality labels, we argue that neoliberal discourses encourage an individualist rejection of labels. However, as we observe throughout this article, sexuality labels are also simultaneously meaningful for women as they demonstrate an extended, reflexive engagement with labels. What is their motivation for asserting that public identity categories do not matter? We suggest that in a homonormative, rural context, there is more to be gained from claiming ordinariness than emphasising minority status. Under neoliberalism, “identity politics" is increasingly used as a derogatory synonym for feminism and anti-heterosexism - akin to complaints of "political correctness gone mad" (Bernstein 
2005: 48). Homonormativity represents individuals as free, neutral citizens, whereas identity politics is reserved for "others," thereby making the notion of the "ordinary" citizen gendered, raced, and classed. For example, as Hekman (2004: 6) argues, white, heterosexual men are never acknowledged as having an identity. Rather, they are represented as the neutral, "abstract citizen" of neoliberalism. Therefore, in neoliberal post-modernity, individual specificity is valued highly, prompting bisexual and queer young women to simultaneously embrace specific sexual identities that establish them as complex individuals, while also allowing them to avoid the political stereotypes associated with more traditional collective identities.

Nevertheless, the ability to claim neutral individuality or "ordinariness" is not only a product of neoliberalism, but is profoundly raced and classed. The white, middle class participants in this study possessed cultural capital that allows them to embrace queer unintelligibility in a way that may be less accessible to others in more marginalised groups (e.g. Yon-Leau and Muñoz-Laboy 2010). As Skeggs (2004: 53) points out, "the method of constructing a biography is seen to be a neutral method, something one just does, rather than something dependent on access to discourse and resources." Indeed, participants in this study who express ambivalence to labels are quintessential neoliberal, post-feminist subjects - young, white, middle-class, and university educated women. These participants portray dwelling on issues of labels and sexual identity as unnecessarily political, restrictive and minoritising in a rural Tasmanian context. Thus, from their positions of privilege, it is arguably easier to reject sexual identity labels because white, middle-class women do not see a need to mobilise for rights based on collective gender and sexual identities. This neoliberal focus on individualism challenges the possibility of collective mobilisation on the basis of 
shared oppressions as women and risks dismantling sexuality as an identity category. Therefore, we argue that contemporary rejections of sexual identity labels are a product of homonormativity or the neoliberal politics of normalisation, even in rural space (Richardson, 2005).

Parallel to their navigation of homonormativity, participants also engage in critical identity work within neoliberalism as they simultaneously incorporate and reject these influences on their understandings of sexuality. Findings reveal that binary definitions of sexuality constitute normativising protocols that invalidate participants' claims to queerness if their experiences do not adhere to expected definitions (Muñoz, 1999: 8). Given that sexual identity is largely defined by sexual activity, bisexuality and other plurisexual labels are seldom viewed as "legitimate" sexual identities in their own right. With these experiences in mind, we suggest that rather than being entirely depoliticised and individualist, participants' rejections of certain identity labels can be interpreted as a disidentificatory "survival strategy" to allay monosexist stigma in homonormative rural contexts where queerness may be less accepted and understood.

In this article, we have argued that Muñoz's disidentification is a useful way to rethink homonormative explanations for young women's sexual self-labelling. Instead of positioning the rejection of sexuality as an entirely neoliberal act, it is also an example of subjects challenging and reinterpreting these cultural forms (Muñoz 1999: 12). In line with Muñoz's (1999) framework, our participants work on identity labels through their reflexive engagement and critical revisions of categories. They work with contemporary neoliberal identificatory structures through questioning the salience of sexual identities in favour of individuality. However, they also work 
against neoliberalism and homonormativity in their attempts to (re)articulate fluid sexual selves that do not always adhere to established sexual meta-narratives.

This article uniquely contributes to theoretical perspectives in sexuality studies by using Muñoz's disidentifications to examine rural bisexual and queer women's sexual self-labeling. Additional research is required to build on the findings of this study. More theoretical considerations of how neoliberalism and homonormativity are specifically deployed in the Australian context would expand scholarship and research in this area. We encourage other Australian feminist and queer scholars to consider how Muñoz's work may apply to gender, sexuality, and race in the Australian context. In particular, additional research in rural sexuality studies is needed given the dearth of literature on rural LGBTQ communities beyond the Global North. Future research should continue to explore the experiences and needs of queer communities of colour, with particular focus on the intersections of race/ethnicity and queerness in Australia.

\section{Acknowledgments}

The authors acknowledge the 2016-2017 associates at the Five College Women's Studies Research Center, in particular, Veronica Zebadua, Banu Subramaniam, Diana Sierra Becerra, Julie de Chantal, Rachel Brown, and Helena Tolvhed for their feedback on earlier drafts of this article. Thanks also to Imelda Whelehan, Katsuhiko Suganuma, Ngaire Donaghue, Louise Richardson-Self, Lucy Tatman, and Eden S. Fay for their additional advice. 


\section{Funding}

The authors acknowledge that this research was conducted with the support of an Australian Government Research Training Program Scholarship.

\section{References}

Adams J, Braun V, and McCreanor T (2014) “Aren’t labels for pickle jars, not people?" Negotiating identity and community in talk about "being gay." American Journal of Men's Health 8(6): 457-469.

Ahmed S (2014) The Cultural Politics of Emotion. Edinburgh: Edinburgh University Press.

Alarie M and Gaudet S (2013) '"I don't know if she is bisexual or if she just wants to get attention": Analyzing the various mechanisms through which emerging adults invisibilize bisexuality.' Journal of Bisexuality 13(2): 191-214.

Albury K (2015) Identity plus? Bi-curiosity, sexual adventurism and the boundaries of "straight" sexual practices and identities. Sexualities 18(5-6): 649-664.

Australian Bureau of Statistics (2014) National Health Survey: First Results. Available at:

http://www.abs.gov.au/ausstats/abs@.nsf/Lookup/by\%20Subject/4364.0.55.001 2014 -15 Main\%20Features Tasmania 10007 (accessed 24 April 2017). 
Australian Bureau of Statistics (2012) State and Territory Statistical Indicators: Tasmania. Available at:

http://www.abs.gov.au/ausstats/abs@.nsf/Lookup/by+Subject/1367.0 2012 Main+Fe atures Tasmania 20 (accessed 23 February 2016).

Babbie, E. (2014) The Basics of Social Research Sixth Edition. Belmont: Wadsworth.

Baird B (2006) Sexual Citizenship in 'the New Tasmania.' Political Geography 25(8): 964-987.

Balsam KF and Mohr JJ (2007) ‘Adaptation to sexual orientation stigma: A comparison of bisexual and lesbian/gay adults.' Journal of Counselling Psychology 54(3): 306-319.

Barefoot KN, Rickard A, Smalley KB, and Warren JC (2015) 'Rural lesbians: Unique challenges and implications for mental health providers.' Journal of Rural Mental Health 39(1): 22.

Bell K and Green J (2016) 'On the perils of invoking neoliberalism in public health critique.' Critical Public Health 26(3): 239-243.

Bell D and Valentine G (1995) Queer country: Rural lesbian and gay lives. Journal of Rural Studies 11(2): 113-122. 
Bishop E (2013) Challenging homogenous representations of rural youth through a reconceptualization of rural young Tasmanian's sexual health strategies. Health Sociology Review 22(2): 124-136.

Boyer, C.R. and M.P. Galupo (2015) “’Prove It!” Same-sex performativity among sexual minority women and men.' Psychology and Sexuality 6(4): 357-368.

Butler J (1993) Bodies that matter: On the discursive limits of sex. New York: Taylor \& Francis.

Callis AS (2014) Bisexual, pansexual, queer: non-binary identities and the sexual borderlands. Sexualities 17(1-2): 63-80.

Chen E (2013) Neoliberalism and popular women's culture: rethinking choice, freedom, and agency. European Journal of Cultural Studies 16(4): 440-452.

Cohen CJ (1997) Punks, Bulldaggers, and Welfare Queens: The radical potential of queer politics? GLQ 3(1): 437-465.

Cohler BJ and Hammack PL (2007) The psychological world of the gay teenager:

Social change, narrative, and "normality." Journal of Youth and Adolescence 36(1): $47-59$.

Coleman-Fountain E (2014) Lesbian and gay youth and the question of labels. Sexualities 17(7): 802-817. 
Corbin J and Strauss A (2015) Basics of Qualitative Research: Techniques and Procedures for Developing Grounded Theory. Fourth Edition. Thousand Oaks: Sage.

Crawford L (2017) A good ol' country time: Does queer rural temporality exist? Sexualities 20(8): 904-920.

Diamond, L. M. (2003) 'Was it a phase? Young women's relinquishment of lesbian/bisexual identities over a 5-year period.' Journal of Personality and Social Psychology 84(2): 352-364.

Duggan, L. (2012) The Twilight of Equality: Neoliberalism, Cultural Politics and the Attack on Democracy. Boston: Beacon Press.

Duggan, L. (2002) "The New Homonormativity: The Sexual Politics of Neoliberalism." in R. Castronovo and D. D. Nelson (Eds) Materializing Democracy: Toward a Revitalized Cultural Politics. Durham: Duke University Press:ićpij $175-94$.

Flanders CE, Robinson M, Legge MM, and Tarasoff LA (2016) 'Negative identity experiences of bisexual and other non-monosexual people: A qualitative report.' Journal of Gay and Lesbian Mental Health 20(2): 152-172

Ghaziani A (2011) Post-Gay Collective Identity Construction. Social Problems 58(1): 99-125. 
Gorman-Murray A, Waitt G and Gibson C (2008) A Queer Country? A case study of the politics of gay/lesbian belonging in an Australian country town. Australian Geographer 39(2): 171-191.

Grant R and Nash M (2018a) "Educating queer sexual citizens? A feminist exploration of bisexual and queer young women's sex education in Tasmania, Australia." Sex Education, 1-16.

Grant R and Nash M (2018b) 'Navigating unintelligibility: Queer Australian young women's negotiations of safe sex and risk.' Journal of health psychology 23(2): 306319.

Grzanka PR, Mann ES, and Elliott S (2016) 'The neoliberalism wars, or notes on the persistence of neoliberalism.' Sexuality Research and Social Policy 13: 297-307.

Halberstam J (2005) In a queer time and place: Transgender bodies, subcultural lives. New York: New York University Press.

Harvey D (2005) A Brief History of Neoliberalism. New York: Oxford University Press.

Hegna K (2007) Coming out, coming into what? Identification and risks in the 'coming out' story of a Norwegian late adolescent gay man. Sexualities 10(5): 582602. 
Hekman S (2004) Private Selves, Public Identities: Reconsidering Identity Politics. University Park: Pennsylvania State University Press.

Hillier L, Harrison L and Bowditch K (1999) "Neverending Love" and "Blowing Your Load": The meanings of sex to rural youth. Sexualities 2(1): 69-88.

Jagose A (1996) Queer theory: An introduction. New York: New York University Press.

Kazyak E (2012) Midwest or lesbian? Gender, rurality and sexuality. Gender and Society 26(6): 825-848.

Kitzinger C (1987) The Social Construction of Lesbianism. London: Sage.

Lea T, de Wit J and Reynolds R (2015) "Post-Gay" Yet? The Relevance of the Lesbian and Gay Scene to Same-Sex Attracted Young People in Contemporary Australia. Journal of Homosexuality. 00: 1-21.

Medina J (2003) Identity Trouble: Disidentification and the problem of difference. Philosophy and Social Criticism 29(6): 655-680.

Muñoz JE (1999) Disidentifications: Queers of colour and the performance of politics. Minneapolis: University of Minnesota Press.

Puri J (2016) Sexualizing Neoliberalism: Identifying technologies of privatization, 
cleansing, and scarcity. Sexuality Research and Social Policy 13: 297-307.

Reinharz S (1992) Feminist Methods in Social Research. New York: Oxford University Press.

Richardson D (2005) Desiring Sameness? The rise of a neoliberal politics of normalisation. Antipode 37(3): 515-535.

Riggs DW (2010) On accountability: towards a white middle-class queer "post identity politics identity politics.” Ethnicities 10(3): 344-357.

Robards B, Churchill B, Vivienne S, Hanckel B and Byron P (2018) 'Twenty years of “cyberqueer": The enduring significance of the internet for young LGBTIQ+ people', in P Aggleton, R Cover, D Leahy, D Marshall and ML Rasmussen (eds) Youth, Sexuality and Sexual Citizenship. London and New York: Routledge: 151-167.

Robinson, M (2013) 'Polyamory and monogamy as strategic identities.' Journal of Bisexuality 13(1): 21-38.

Robinson KH, Bansel P, Denson N, Overden G and Davies C (2014) Growing Up

Queer: Issues facing young Australians who are gender variant and sexuality diverse. Young and Well Cooperative Research Centre, Melbourne.

Rose N (1999) Powers of Freedom: Reframing Political Thought. London:

Cambridge University Press. 
Rupp, L. J. and Taylor, V. (2010) 'Straight girls kissing.' Contexts 9(3): 28-32.

Sanchez AA (2017) 'The whiteness of 'coming out': Culture and identity in the disclosure narrative.' Archer Magazine 7 July 2017 available at:

http://archermagazine.com.au/2017/07/culture-coming-out/ (viewed 26 Oct 2017).

Savin-Williams RC (2005) The New Gay Teenager. Cambridge: Harvard University Press.

Sedgwick EK (1990) Epistemology of the Closet. Berkeley: University of California Press.

Seidman S (2013) Beyond the closet: The transformation of gay and lesbian life.

London and New York: Routledge.

Senior K, Helmer J, Chenhall R and Burbank V (2014) "Young, clean and safe?" Young people's perceptions of risk from sexually transmitted infections in regional, rural and remote Australia. Culture, Health and Sexuality 16(4): 453-466.

Skeggs B (2004) Class, Self, Culture. Routledge: London.

Stein A (2010) The Incredible Shrinking Lesbian World and other Queer Conundra. Sexualities 13(1): 21-32. 
Yon-Leau C and Muñoz-Laboy M (2010) “ “I don't like to say that I'm anything:” Sexuality Politics and Cultural Critique Among Sexual-Minority Latino Youth.' Sex Research and Social Policy 7: 105-117. 